\title{
PENERAPAN METODE TANYA JAWAB DENGAN VARIASI MEDIA PEMBELAJARAN TERHADAP PENINGKATAN HASIL BELAJAR SISWA DALAM MATA PELAJARAN PPKN PADA SISWA KELAS VII D SMP DWIJENDRA DENPASAR TAHUN PELAJARAN 2018/2019
}

\author{
I G A Mas Darwati \\ Program Studi Pendidikan Pancasila dan Kewarganegaraan, Fakultas Keguruan Dan Ilmu Pendidikan \\ Universitas Dwijendra Denpasar \\ email : masdarwati@undwi.ac.id \\ Veronika Rambu Padu Jabu \\ Program Studi Pendidikan Pancasila dan Kewarganegaraan, Fakultas Keguruan Dan Ilmu Pendidikan \\ Universitas Dwijendra Denpasar \\ email : veronika@gmail.com
}

\begin{abstract}
Abstrak
Dalam proses pendidikan metode mempunyai kedudukan yang begitu penting dalam upayamencapai tujuankarena metode merupakan sarana penunjang yang membantu kelancaran jalannya proses belajar mengajar. Metode adalah cara yang digunakan untuk mengimplementasikan rencana yang sudah disusun dalam kegiatan nyata agar tujuan yang telah disusun dapat terapai secara optimal. Adapun rumusan masalah yaitu: Berdasarkan permasalahan di atas, rumusan masalah dalam penelitian tindakan kelas ini adalah Apakah melalui upaya penerapan metode Tanya jawab bervariasi media pembelajaran hasil belajar siswa akan, meningkat pada matapelajaran PPKn pada siswa kelas VII D SMP Dwijendra Denpasar tahun pelajaran 2018/2019?. Penelitian ini bertujuan untuk mengetahui upaya yang dilakukan untuk meningkatkan penerapan metode Tanya jawab bervariasi media pembelajaran dalam hasil belajar siswa pada mata pelajaran PPKn pada siswa kelas VII D SMP Dwijendra Denpasar tahun pelajaran 2018/2019. Penelitian ini dilakukan dengan 2 siklus yaitu siklus pertama dan siklus kedua.metode yang digunakan dalam pengumpulan data adalah test, observasi, data lapangan. Analisis data yang digunakan yaitu deskriptif kuantitatif. Hasil analisis data diperoleh bahwa pelaksanaan pembelajaran dengan penerapan metode Tanya jawab dengan variasi media pembelajaran di kelas VII D SMP Dwijendra Denpasar dapat meningkatkan aktivitas dan hasil belajar siswa. Peningkatan aktivitas dan hasil belajar siswa ditandai dengan meningkatkan hasil belajar siswa pada setiap test akhir siklus. Tingkatan rata-rata pencapaian skor saat pre test sebesar $7.338 \%$ rata-rata pencapaian skor saat test siklus 1 sebesar $7.725 \%$ dan rata-rata pencapaian skor saat test siklus 2 sebesar.8,612\%.Sedangkan ketuntasan belajar siswa saat pre test sebesar 45,16 dan post siklus 2 meningkat dengan signitifkan sebesar $93.54 \%$ berdasarkan hasil belajar siswa di uraikan dapat di simpulkan bahwa, proses pembelajaran menggunakan penerapan metode Tanya jawab dengan variasi media pembelajaran sangat efektif bila di terapkan di sekolah (dikelas).
\end{abstract}

Kata kunci: Metode tanya jawab, variasi media pembelajaran, hasil belajar

\begin{abstract}
In the process of education the method has a very important position in trying to achieve goals because the method is a supporting tool that helps the smooth running of the learning process. The method is a method used to implement a plan that has been prepared in real activities so that the objectives that have been prepared can be achieved optimally. The formulation of the problem are: Based on the problems above, the formulation of the problem in this class action research is whether through the application of the question and answer method varies the learning media of student learning outcomes will, increase in PPKn subjects in class VII D students at Dwijendra Denpasar Middle School in 2018/2019 ? This study aims to determine the efforts made to improve the application of the question and answer method of varying learning media in student learning outcomes in PPKn subjects in class VII D of SMP Dwijendra Denpasar in the academic year 2018/2019. This research was conducted in 2 cycles, the first cycle and the second cycle. The methods used in data collection were test, observation, field data. Analysis of the data used is descriptive quantitative. The results of the analysis of the data obtained that the implementation of learning by
\end{abstract}


applying the question and answer method with a variety of learning media in class VII D of Dwijendra Denpasar Junior High School can improve student learning activities and outcomes. Increased student activity and learning outcomes are marked by increasing student learning outcomes at each end of the test cycle. The average level of achievement score when pre-test amounted to 7,338\% the average achievement score during the first cycle test was 7,725\% and the average achievement score during the second cycle test was $8,612 \%$. While the completeness of student learning during pre-test was 45,16 and post cycle 2 increased with a significance of $93.54 \%$ based on student learning outcomes described can be concluded that, the learning process using the question and answer method with a variety of instructional media is very effective when applied at school (in class).

Keywords: Question and answer method, variations in learning media, learning outcomes

\section{PENDAHULUAN}

Metode Tanya sering kali dikaitkan dengan diskusi, seminar, dan kegiatan ilmiah lain yang di dalamnya terjadinya proses Tanya jawab.pada dasarnya dalam beberapa kegiatan ilmiah tersebut memiliki persamaanya itu samasama terjadi proses Tanya jawab untuk bertukar pengetahuan dan informasi yang belum jelas. Secara umum Tanya jawab biasa di lakukan dalam kegiatan pembelajaran seperti ketika diskusi. Sebenarnya metode Tanya jawab sendiri dapat dilakukan terpisah secara khusus pada proses pembelajaran.

Metode Tanya jawab dunia pendidikan merupakan salah satu metode pembelajaran metode konvensial yang sering digunakan dalam proses belajar mengajar di kelas, selain metode ceramah dan diskusi. Metode memang tepat digunakan untuk menjawab materi yang dirasa belum di pahami oleh siswa. Hal ini juga senada dengan pendapatnya Roestiyah (2008:129) yang menyatakan bahwa : "Metode Tanya jawab merupakan suatu teknik untuk memberi motivasi siswa agar bangkit pemikirannya untuk bertanya, selama mendengarkan pelajaran atau guru yang mengajukan pertanyaan-pertanyaan itu, siswa menjawab. Pasti saja pertanyaan-pertanyaan itu mengenai isi pelajaran yang sedang diajarkan guru;dan siswa seharusnya sudah mengerti ;atau pertanyaan yang lebih luas asal berkaitan dengan pelajaran atau juga mungkin pengalaman yang dihayati dengan Tanya jawab itu, pelajaran akan lebih mendalam dan meluas."

Penerapan metode Tanya jawab dengan variasi media pembelajaran yang efektif meningkatkan hasil belajar siswa.media adalah bahan,alat dan teknik yang digunakan dalam pembelajaran memiliki manfaat yang besar dan dalam memudahkan siswa mempelajari materi pelajaran.Tugas seorang guru dalam menyampaikan materi pelajaran kepada siswa tidaklah mudah.Guru harus memiliki berbagai kemampuan yang dapat menunjang tugasnya agar tujuan pendidikan dapat dicapai. Salah satu kemampuan yang harus dimiliki oleh seorang guru dalam meningkatkan kompetensi profesinya ialah kemampuan mengembangkan model pembelajaran.

Dalam proses pendidikan metode mempunyai kedudukan yang begitu penting dalam upayamencapai tujuankarena metode merupakan sarana penunjang yang membantu kelancaran jalannya proses belajar mengajar. Metode adalah cara yang digunakan untuk mengimplementasikan rencana yang sudah disusun dalam kegiatan nyata agar tujuan yang telah disusun dapat terapai secara optimal. 
Dalam mengembangkan model pembelajaran seorang guru harus dapat menyesuaikan antara model yang dipilihnya dengan kondisi siswa, materi pelajaran, dan sarana yang ada. Oleh karena itu, guru harus menguasai beberapa jenis model pembelajaran agar proses belajar mengajar berjalan lancar dan tujuan penerapan stimulus dengan Metode Tanya Jawab Terhadap peningkatan hasil belajar siswa dalam pembelajaran PPKn (Penelitian Tindakan Kelas Pada Siswa Kelas VII D SMP Dwijendra) dalam bahan mengajar yang ingin dicapai dapat terwujud.

Tugas seorang guru dalam menyampaikan materi mata pelajaran padaa siswa tidaklah mudah. Guru harus memiliki berbagai kemampuan yang dapat menunjang tugasnya agar tujuan pendidikan dapat dicapai. Salah satu kemampuan yang di atur kompetensi profesinya ialah kemampuan memgembangkan model pembelajaran. Dalam rangka meningkatan persentase kelulusan atau kenaikan siswa kelas VII D tersebut, tentunya guru dituntut merancang model pembelajaran yang lebih tepat serta penerapan media pembelajaran yang variatif.

Proses belajar mengajar merupakan interaksi yang dilakukan antara guru dengan peserta didik dalam suatu pengajaran untuk mewujudkan tujuan yang di tetapkan berbagai pendekatan yang digunakan dalam pembelajaran dalam mengajar. Metode adalah cara yang telah teratur dan berpikir baik baik untuk mencapai suatu maksud.maka metode dapat di artikan sebagai jalan atau cara yang harus dilalui untuk mencapai tujuan tertentu.
Pembelajaran adalah suatu usaha yang di sengaja bertujuan dan terkendali agar orang lain belajar terjadi perubahan yang relative menetap pada diri orang lain. Usaha ini dilakukan oleh seseorang atau suatu tim yyang memiliki kemampuan dan kompetensi dalam merancang dan atau mengembangkan sumber belajar yang di perlukan.

Untuk itu diperlukan suatu metode pembelajaran yamg dapat meningkatkan interaksi antara guru dengan siswa dan antara siswa. Salah satu metode tanya jawab yg dapat diterapkan adalah metode tanya jawab. Guru sebagai pengajar dan pendidik harus dapa menciptakan kondisi belajar yang kondusif dan dan menyenangkan dalam proses pembelajaran dan mampu menggunakan metode pembelajaran yang tepat sehingga dan meningkatkan hasil belajar siswa.

Belajar telah menjadi bagian dari kehidupan manusia. Belajar menjadi seiring dengan pertumbuhan dan perkembangan manusia.bagi seorang pelajar,belajar mereupakan sebuah kewajiban.hasil belajar adalah kemampuan-kemampuan yang di miliki siswa setelah ia menerima pengalaman belajarnya. Catatan lapangan sehubungan dengan hal-hal yang terjadi selama pembelajaran berlangsung. Data hasil Observasi adalah sebagai berikut: (1) Suasana masih gundah saat siswa melakuakan kerja kelompok. (2) Beberapa siswa kurang berkonsentrasi belajar dalam dikusi, hal ini terlihat masih ada siswa yang diam dan bercanda pada saat belajar kelompok. (3) Saat peneliti meminta untuk mempresentasikan hasil kerja siswa masih saling menujuk temannya untuk kedepan. (4) 
Masih banyak siswa yang mengobrol saat peneliti memberikan pembelajaran tentang materi pembelajaran.

\section{METODE}

Lokasi penelitian ini dilaksanakan di SMP Dwijendra Denpasar. Subyek dari penelitian ini adalah siswa kelas VII D. Objek dari penelitian ini adalah metode Tanya jawab dan hasil belajar siswa kelas VII D Teknik pengumulan data dalam penelitian ini menggunakan Teknik Observasi, Test, Catatan hasil refleksi dan Dokumentasi. Analisis data dalam PTK ini dilakukan sejak awal, artinya analisis data dilakukan tahap demi tahap atau siklus demi siklus. Hal ini sesuai dengan pendapat Miles dan Huberman dalam Rochiati Wiriaatmaja (2005:139) bahwa "the ideal model for data collection and analysis is one that interweaves them form the beginning". Ini berarti model ideal dari pengumpulan data dan analisis adalah yang secara bergantian berlangsung sejak awal. Kegiatan analisis data akan dilakukan mengacu pada pendapat Rochiati Wiriaatmaja, (2005:135-151) dengan melakukan catatan refleksi, yakni pemikiran yang timbul pada saat mengamati dan merupakan hasil proses membandingkan, mengaitkan atau menghubungkan data yang ditampilkan dengan data sebelumnya.

\section{HASIL DAN PEMBAHASAN}

\section{Siklus 1}

Pada tahap pelaksanaan, siklus pertama direncanakan dilaksanakan dalam satu pertemuan, dalam pertemuan pertama ini 1 jam digunakan untuk pelaksanaan pembelajaran PPKN Bab 6 Kelas VII SMP Dwijendra
Denpasar dan satu (1) jam digunakan untuk post test 1. Adapun materi yang di ajarkan adalah daerah dalam kerangka negara kesatuan republik Indonesia.

Dalam tahap pelaksanaan siklus pertama direncanakan dalam satu kali pertemuan, dan dalam satu hari tersebut, 1 jam pelajaran digunakan untuk pelaksanaan pembelajaran dengan penerapan metode Tanya jawab dengan variasi media pembelajaran PPKn

Pelaksanaan tindakan ini dilaksanakan pada hari selasa 23 mei 2019 dilaksanakan pada pukul 08;15 s.d 11;15 WIB, di kelas VII D SMP Dwijendra Denpasar. Pada pertemuan ini peneliti di bantu oleh satu orang teman sebagai tim kolaborasi yang bertindak sebagain observer. Sebelum pelajaran dimulai peneliti terlebih dahulu mengkondisikan kelas, agar siswa benar-benar siap untuk menerima pelajaran serta memberi motivasi kepada siswa agar mereka antusias dalam belajar.

Kegiatan diawali dengan mengucap salam terlebih dahulu, Do'a tidak dibacakan karena pada saat dilakukan penelitian sudah masuk pada jam pelajaran kedua sebab Doa telah dibacakan pada jam pertama diawali. Selanjut peneliti menyapaikan tujuan pembelajaran yang ingin di capai, serta memotifasi siswa berpartisipasi aktif dalam pelajaran

Kemudian peneliti memberikan materi secara global bahwa pembelajaran kali ini mengunakan model Metode Tanya jawab dengan bantuan buku pelajaran Ppkn BAB 6 . Dan selanjutnya peneliti memberitahu siswa tentang materi yang akan disampaikan, kemudian peneliti membagi siswa menjadi lima 
kelompok secara heterogen, karena saat dimulainya penelitian siswa yang hadir berjumlah 31 siswa. Setiap kelompok terdiri 5 siswa dan 1 kelompok terdiri dari 5 siswa.

Setelah terbentuk kelompoknya masingmasing, kemudian peneliti menyampaikan atau mengajukan pertanyaan yang berkaitan dengan materi "Daerah dalam Kerangka NKRI". Kemudian peneliti memberikan kesempatan kepada siswa untuk berdiskusi dengan kelompoknya. Sementara siswa berdiskusi peneliti berkeliling untuk mengamati kegiatan masing-masing siswa, peneliti juga membimbing siswa untuk cepat menyelesaikan tugasnya dengan baik dan memfasilitasi siswa membuat laporan baik tertulis maupun lisan. Peneliti memberikan waktu 30 menit.

Peneliti juga membimbing kelompok lain untuk mengomentari hasil presentasi. Setelah masing-masing kelompok mempresentasikan hasil kerjanya peneliti memberikan penguatan terhadap materi yang telah dipresentasikan dan peneliti memberikan kesempatan kepada siswa yang belum jelas untuk bertanya.

Memasuki kegiatan pembelajaran akhir, peneliti Bersama siswa membuat simpulan dari hasil diskusi dan mengingatkan siswa untuk mempelajari kembali materi yang telah disampaikan oleh peneliti. Kegiatan pembelajaran pada pertemuan satu ini diakhiri dengan mengucapkan salam

Setelah selesai proses pembelajaran, peneliti langsung berkoordinasi dengan teman yang melakukan observasi terhadap aktivitas siswa selama proses pembelajaran berlangsung

Tabel 1. Tarat Nilai Pengamatan Aktivitas Siswa

\begin{tabular}{|l|l|c|c|l|}
\hline No & \multicolumn{1}{|c|}{ Aktivitas } & Nilai huruf & Bobot & \multicolumn{1}{|c|}{ Predikat } \\
\hline 1 & $86-100 \%$ & A & 4 & Sangat baik \\
\hline 2 & $76-85 \%$ & B & 3 & Baik \\
\hline 3 & $60-75 \%$ & C & 2 & Cukup \\
\hline 4 & $55-59 \%$ & D & 1 & Kurang \\
\hline
\end{tabular}

Maka nilai yang diperoleh siswa berada dalam kategori cukup. Karena penelitian ini belum mencapai nilai ketuntasan yang sudah ditetapkan yaitu $80 \%$ maka peneliti memutuskan untuk melanjutkan untuk penelitian ini pada tahap selanjutnya siklus 2 .

Adapun data hasil test akhir siswa disajikan dalam tabel berikut:

Tabel 2. Data Hasil Siklus 1

\begin{tabular}{|c|c|c|c|c|c|}
\hline NO & Nama Siswa & L/P & Nilai & \multicolumn{2}{|c|}{$\begin{array}{c}\text { Ketuntasan } \\
\text { Belajar }\end{array}$} \\
\cline { 4 - 7 } & & & & Ya & Tidak \\
\hline 1 & Agung Ratih Anjaswari, I Gusti Ayu & & & & \\
\hline
\end{tabular}




\begin{tabular}{|c|c|c|c|c|c|}
\hline 2 & Agus Sandhika Nugraha, I Wayan & $\mathrm{L}$ & 70 & & $\checkmark$ \\
\hline 3 & Agus Saputra Kadek & $\mathrm{L}$ & 80 & $\sqrt{ }$ & \\
\hline 4 & Agus Triwiguna Wicaksana,I Komang & $\mathrm{L}$ & 70 & & $\checkmark$ \\
\hline 5 & Agus Wikananta Dhyasa, Made & $\mathrm{L}$ & 75 & & $\checkmark$ \\
\hline 6 & Anggira Anggi Cahyani,A. Agung & $\mathrm{P}$ & 80 & $\sqrt{ }$ & \\
\hline 7 & Ari Cahaya Pradewi, Made & $\mathrm{P}$ & 80 & $\checkmark$ & \\
\hline 8 & Ari Restasiah Saputra, I Kadek & $\mathrm{L}$ & 80 & & $\sqrt{ }$ \\
\hline 9 & Ayu Kireina Listari, I Gusti Agung & $\mathrm{P}$ & 90 & $\sqrt{ }$ & \\
\hline 10 & Bagus Pradyana, I Made & $\mathrm{L}$ & 75 & & $\sqrt{ }$ \\
\hline 11 & Bagus sudewa, I gusti ngurah & $\mathrm{P}$ & 85 & $\checkmark$ & \\
\hline 12 & Chelsea devya kraanti,ni made & $\mathrm{P}$ & 75 & $\checkmark$ & \\
\hline 13 & Danu Sanjitama Putra,A .A.Ngurah & $\mathrm{L}$ & 60 & & $\sqrt{ }$ \\
\hline 14 & Darma Adi Wacika, I Wayan & $\mathrm{L}$ & 90 & $\sqrt{ }$ & \\
\hline 15 & Deswita Dewi ,Ni Putu & $\mathrm{P}$ & 65 & & $\sqrt{ }$ \\
\hline 16 & Gayatri Krisna, I Gustri Ayu & $\mathrm{P}$ & 85 & $\sqrt{ }$ & \\
\hline 17 & Govin Aditya Kincana,I Putu & $\mathrm{L}$ & 90 & $\sqrt{ }$ & \\
\hline 18 & Mas Ayu Klarita,Ni Kadek & $\mathrm{P}$ & 80 & & $\checkmark$ \\
\hline 19 & Mesya Shindhya Gandhari,I Gusti Ayu & $\mathrm{P}$ & 85 & $\sqrt{ }$ & \\
\hline 20 & Nia Febriyanti, Ni Luh Putu & $\mathrm{P}$ & 70 & & $\checkmark$ \\
\hline 21 & Nia Paramitha, Cokorda Istri & $\mathrm{P}$ & 80 & $\sqrt{ }$ & \\
\hline 22 & Nova Restiawan, Putu & $\mathrm{L}$ & 65 & & $\sqrt{ }$ \\
\hline 23 & Praditya Putra, I Putu Adi & $\mathrm{L}$ & 85 & $\sqrt{ }$ & \\
\hline 24 & Pradyana, Anak Agung Ngurah & $\mathrm{L}$ & 70 & & $\checkmark$ \\
\hline 25 & Putu Pradnya Sari,Anak Agung & $\mathrm{P}$ & 85 & $\checkmark$ & \\
\hline 26 & Richelle Prameswari Khrisnadevypatera & $\mathrm{P}$ & 80 & $\sqrt{ }$ & \\
\hline 27 & Sinta Cipta Dewi,Ni Putu & $\mathrm{P}$ & 65 & & $\sqrt{ }$ \\
\hline 28 & Teruna Yoga,Wayan & $\mathrm{L}$ & 80 & $\sqrt{ }$ & \\
\hline 29 & Windu Adi Semara, I Ketut & $\mathrm{L}$ & 65 & & $\checkmark$ \\
\hline 30 & Winni Claudia Shafira,Dewa Ayu & $\mathrm{P}$ & 80 & $\checkmark$ & \\
\hline 31 & Yana Dharma Sumita, I Putu & $\mathrm{L}$ & 75 & & $\sqrt{ }$ \\
\hline \multicolumn{2}{|c|}{ Jumlah Skor Yang Di Peroleh } & & 2.395 & & \\
\hline & Rata-Rata & & $\mathbf{7 . 7 2 5}$ & & \\
\hline & Jumlah Skor Maksimal & & 3,100 & & \\
\hline & $\mathbf{K K M} \geq \mathbf{8 0}$ & & 18 & & \\
\hline & $\mathbf{N} \leq \mathbf{K M M}$ & & 13 & & \\
\hline
\end{tabular}

Berdasarrkan tabel diatas dapat diketahui

bahwa dengan menggunakan metode penerapan metode Tanya jawab, hasil test 1 siswa yang

$$
\begin{aligned}
\mathrm{P} & =\frac{\text { jumlah siswa yang tuntas }}{\text { jumlah siswa maksimal }} \times 100 \% \\
\mathrm{P} & =\frac{18}{31} \times 100 \% \\
& =58,06 \%
\end{aligned}
$$

tuntas belajar berjumlah 18 siswa. Hasil test pada siklus 1 ini diperoleh nilai rata-rata 7.725 $\%$ 
Prasentase ketuntasan belajar pada siklus 1 adalah $31 \%$ yang berarti bahwa presentase ketuntasan belajar siswa masih dibawah kriteria ketuntasan yang telah ditentukan, yaitu $80 \%$ dengan demikian masih diperlukan siklus berikut untuk membuktikan bahwa penerapan metode tanya jawab mampu meningkatkan hasil belajar siswa

Setiap akhir siklus dilakukan refleksi didasarkan pada hasil observasi, catatan lapangan dan hasil test akhir siklus. Hal ini berlanjutan untuk perbaikin preses bembelaran yang akan diterapkan pada siklus berikutnya. Pelaksanaan kegiatan pembelajaran pada siklus 1 masih banyak kekurangannya. Berdasarkan hasil pengamatan terhadap masalah-masalah selama pelaksanaan proses pembelajaran pada siklus 1 dari hasil observasi, catatan lapangan dan post test 1 , diperoleh hasil sebagai berikut: (1) Siswa masih kurang aktif dalam menyampaikan pendapat dalam belajar kelompok. (2) Pada waktu akan presentasi masih ada saling berdebat untuk menentukan siapa yang akan menjadi wakil dalam mempresentasikan hasil kerja kelompok. (3) Suasana kelas kurang kondusif dan belum terkondisikan dengan baik.

Masalah-masalah diatas timbul disebabkan oleh factor antara lain sebagai berikut: (1) Siswa belum terbiasa dengan penerapan metode tannya jawa dengan variasi media pembelajaran, (2) Siswa masi terlihat pasif dalam belajar kelompok, hanya beberapa siswa yang aktif melakukan diskusi, dan siswa lain hanya melihat. (3) Siswa masih kurang percaya diri dengan kemampuan yang dimilikinya, baik dalam mengerjakan tugas dan memprestasikan.

Ditinjau dari beberapa maslah dan faktor-faktor penyebabnya, maka perlu dilakukan beberpa tindakan untuk mengatasinya antara lain; (1) Peneliti harus menjelaskan kemudahan dan manfaat yang diperoleh dalam belajar kelompok. (2) Peneliti berusaha untuk mengaktifkan dan mendorong siswa untuk bekerja sama dengan kelompoknya. Sehingga, mereka yang pasif mau mengemukakan pendapatnya dalam kelompok. Meningkatkan rasa percaya diri siswa akan kemampuan yang dimiliki, menayakin siswa bahwa pekerjaan yang dikerjakan sendiri akan memberikan hasil yang baik.

Dari uraian diatas, maka secara umum pada siklus 1 belum menujukkan adanya partisipasi aktif dari siswa. Oleh karena itu, penelitian perlu untuk dilanjutkan pada siklus II agar partisipasi belajar PPKn siswa bisa meningkatkan sesuai dengan yang diharapkan.

\section{Siklus II}

Pada siklus II dilaksanakan I kali pertemuan. Dengan alokasi waktu 2 X 60 menit. Dilaksanakan pada hari selasa tanggal 20 mei 2019. Dengan berrkonsultasi dengan guru mata pelajaran agama agar bisa diizinkan untuk memakai jam pelajaran agama untuk melanjutkan penelitian akhir siklus II karena jadwal yang ditetapkan setiap hari senin pada jam kedua siswaa kelas VII SMP Dwijendra akan melakukan ulangan. Setelah guru mata pelajaran agama mengijinkan untuk memakai jam pelajarannya maka penelitian siklus II dilanjutkan. Adapun materi yang diajarkan 
adalah "Daerah dalam kerangka negara kesatuan republic Indonesia".

Pada pertemuan ini dilaksanakan pada hari selasa tanggal 11 maret 2019. Pada pertemuan ini peneliti ditemani oleh seorang teman sebagai observer. Sebelum peneliti melakuan post test ke II, peneliti mengulang sedikit materi yang telah diajarkan kemudian peneliti memberitahu siswa untuk menyiapkan alat tulis dan kertas yang akan digunakan untuk post test II. Kemudian peneliti menjelaskan tentang perintah dan prosedur pengejaannya, kemudian siswa mengerjakan soal-soal tersebut peneliti mengemati jalannya kegiatan. Setelah siswa selesai mengerjakan soal-soal test tersebut peneliti meminta siswa untuk mengumpulkan hasil kerja mereka.
Kegiatan penutup pada pertemuan ini peneliti memberikan kesempatan kepada siswa untuk bertanya tentang kesulitan dalam mengerjakan test yang berusaha dikerjakan. Kemudian peneliti menutup kegiatan pembelajaran dengan mengucapkan salam.

Pada tahap observasi siklus II ini sama halnya pada siklus 1 , yaitu dilakukan pada saat pembelajaran sedang berlangsung. Observer pada peneliti ini dilakukan oleh teman sejawat. Observer ini dilakukan sesuai dengan pedoman observasi terlampir.

Sesuai taraf keberhasilan yang telah di tentukan yaitu:

Tabel 3. Taraf Nilai Pengamatan Aktivitas Siswa Siklus II

\begin{tabular}{|l|l|c|c|c|}
\hline No & Aktivitas & Nilai Huruf & Bobot & Predikat \\
\hline 1 & $86-100 \%$ & A & 4 & Sangat baik \\
\hline 2 & $76-85 \%$ & B & 3 & Baik \\
\hline 3 & $60-75 \%$ & C & 2 & Cukup \\
\hline 4 & $55-59 \%$ & D & 1 & Kurang \\
\hline
\end{tabular}

Setelah melaksanakan penerapan metode Tanya jawab siswa pada pertemuan pertama, maka pertemuan kedua dilaksanakan test akhir untuk mengtahui kemampuan siswa dalam memehami materi pelajaran yang telah disampaikan.

Adapun data hasil test akhir siswa disajikan dalam tabel berikut ini

Tabel 4. hasil post test akhir pada siklus II

\begin{tabular}{|c|c|c|c|c|c|}
\hline \multirow[t]{2}{*}{ NO } & \multirow[t]{2}{*}{ Nama Siswa } & \multirow[t]{2}{*}{$\mathbf{L} / \mathbf{P}$} & \multirow[t]{2}{*}{ Nilai } & \multicolumn{2}{|c|}{$\begin{array}{c}\text { Ketuntasan } \\
\text { Belajar }\end{array}$} \\
\hline & & & & $\mathrm{Ya}$ & Tidak \\
\hline 1 & Agung Ratih Anjaswari, I Gusti Ayu & $\mathrm{P}$ & 90 & $\sqrt{ }$ & \\
\hline 2 & Agus Sandhika Nugraha, I Wayan & $\mathrm{L}$ & 85 & $\sqrt{ }$ & \\
\hline 3 & Agus Saputra Kadek & $\mathrm{L}$ & 85 & $\sqrt{ }$ & \\
\hline 4 & Agus Triwiguna Wicaksana,I Komang & $\mathrm{L}$ & 80 & $\sqrt{ }$ & \\
\hline 5 & Agus Wikananta Dhyasa, Made & $\mathrm{L}$ & 90 & $\sqrt{ }$ & \\
\hline 6 & Anggira Anggi Cahyani,A. Agung & $\mathrm{P}$ & 85 & $\sqrt{ }$ & \\
\hline 7 & Ari Cahaya Pradewi, Made & $\mathrm{P}$ & 90 & $\checkmark$ & \\
\hline 8 & Ari Restasiah Saputra, I Kadek & $\mathrm{L}$ & 85 & $\sqrt{ }$ & \\
\hline 9 & Ayu Kireina Listari, I Gusti Agung & $\mathrm{P}$ & 95 & $\sqrt{ }$ & \\
\hline
\end{tabular}




\begin{tabular}{|c|c|c|c|c|c|}
\hline 10 & Bagus Pradyana, I Made & $\mathrm{L}$ & 80 & $\checkmark$ & \\
\hline 11 & Bagus sudewa, I gusti ngurah & $\mathrm{P}$ & 80 & $\checkmark$ & \\
\hline 12 & Chelsea devya kraanti,ni made & $\mathrm{P}$ & 85 & $\checkmark$ & \\
\hline 13 & Danu Sanjitama Putra,A .A.Ngurah & $\mathrm{L}$ & 90 & $\checkmark$ & \\
\hline 14 & Darma Adi Wacika, I Wayan & $\mathrm{L}$ & 90 & $\sqrt{ }$ & \\
\hline 15 & Deswita Dewi ,Ni Putu & $\mathrm{P}$ & 70 & & $\sqrt{ }$ \\
\hline 16 & Gayatri Krisna, I Gustri Ayu & $\mathrm{P}$ & 85 & $\sqrt{ }$ & \\
\hline 17 & Govin Aditya Kincana,I Putu & $\mathrm{L}$ & 90 & $\sqrt{ }$ & \\
\hline 18 & Mas Ayu Klarita,Ni Kadek & $\mathrm{P}$ & 95 & $\checkmark$ & \\
\hline 19 & Mesya Shindhya Gandhari,I Gusti Ayu & $\mathrm{P}$ & 85 & $\sqrt{ }$ & \\
\hline 20 & Nia Febriyanti, Ni Luh Putu & $\mathrm{P}$ & 85 & $\checkmark$ & \\
\hline 21 & Nia Paramitha, Cokorda Istri & $\mathrm{P}$ & 90 & $\sqrt{ }$ & \\
\hline 22 & Nova Restiawan, Putu & $\mathrm{L}$ & 80 & $\checkmark$ & \\
\hline 23 & Praditya Putra, I Putu Adi & $\mathrm{L}$ & 90 & $\sqrt{ }$ & \\
\hline 24 & Pradyana, Anak Agung Ngurah & $\mathrm{L}$ & 85 & $\checkmark$ & \\
\hline 25 & Putu Pradnya Sari,Anak Agung & $\mathrm{P}$ & 80 & $\checkmark$ & \\
\hline 26 & Richelle Prameswari Khrisnadevypatera & $\mathrm{P}$ & 90 & $\sqrt{ }$ & \\
\hline 27 & Sinta Cipta Dewi,Ni Putu & $\mathrm{P}$ & 75 & & $\sqrt{ }$ \\
\hline 28 & Teruna Yoga,Wayan & $\mathrm{L}$ & 90 & $\sqrt{ }$ & \\
\hline 29 & Windu Adi Semara, I Ketut & $\mathrm{L}$ & 80 & $\checkmark$ & \\
\hline 30 & Winni Claudia Shafira,Dewa Ayu & $\mathrm{P}$ & 85 & $\checkmark$ & \\
\hline 31 & Yana Dharma Sumita, I Putu & $\mathrm{L}$ & 85 & $\checkmark$ & \\
\hline \multicolumn{2}{|c|}{\begin{tabular}{|l|} 
Jumlah Skor Yang Di Peroleh \\
\end{tabular}} & & 2,670 & & \\
\hline & Rata-Rata & & 85.48 & & \\
\hline & Jumlah Skor Maksimal & & 3,100 & & \\
\hline & $K K M \geq 80$ & & 29 & & \\
\hline & $\mathbf{N} \leq \mathbf{K M M}$ & & 2 & & \\
\hline
\end{tabular}

Berdasarkan tabel diatas dapat diketahui bahwa dengan menggunakan penerapan metode Tanya jawab dengan variasi media pembelajaran dapat meningkat, hasil post test kedua siswa yang tuntas belajar berjumlah 31 siswa.

Hasil test akhir pada siklus II ini peroleh nilai rata-rata 86.12. Dari hasil test akhir pada siklus II

$$
\begin{aligned}
& \mathrm{P}=\frac{\text { jumlah siswa yang tuntas }}{\text { jumlah maksimal }} \times 100 \% \\
& \mathrm{P}=\frac{29}{31} \times 100 \% \\
& \mathrm{P}=93,54
\end{aligned}
$$

Presentasi ketuntasan belajar pada siklus II adalah 31 yang berarti bahwa presentase ketuntasan tersebut, hasil belajar siswa sudah mengalami peningkatan dibandingkan hasil test siklus I.

Jadi, dapat diketahui dengan mengunakan penerapan metode Tanya jawab dengan variasi media pembelajaran, hasil post test siswa yang tuntas belajar sebanyak 31 siswa yang tuntas belajar sebanyak 31 siswa. belajar siswa sudah memenuhi kriteria ketuntsan yang telah ditentukan yaitu $80 \%$. 
Berdasar hasil observasi, catatan lapangan dan hasil test akhir padat diperoleh beberapa hal, antara lain sebagai berikut. (1) Aktivitas siswa sudah menunjukkan tingkat keberhasilan yang baik meskipun semua belum mencapai kriteria yang inginkan. (2) Berdasarkan test akhir siklus II, dan membandingkan dengan siklus I, hasil belajar siswa menunjukkan peningkatan.

Dari uraian diatas dapat disimpulkan bahwa penerapan metode Tanya jawab dengan variasi media pembelajaran pada siklus II dapat dikatakan berhasil dan tidak diperlukan siklus selanjutnya, sehingga tahap berikutnya adalah penulisan laporan.

Berdasarkan temuan yang diperoleh dari pelaksanaan penelitian di kelas VII D SMP Dwijendra Denpasar sebagai berikut: (1) Siswa merasa senang belajar secara kelompok, karena dengan cara seperti ini siswa dapat bertukar pikiran/pendapat dengan teman. (2) Siswa lebih mudah memahami dan lebih termotivasi dan bersemangat dalam mengikuti proses pembelajaran. (3) Dengan metode yang baru dan bervariasi siswa tidak merasa bosan. (4) Dan dengan mengunakan penerapan metode tanaya jawab dengan variasi media pembelajaran siswa mengelami peningkatan.

\section{Pembahasan Hasil Penelitian}

Penelitian ini dilakukan sebagai upaya untuk meningkatkan hasil belajar siswa dalam pembelajaran PPKn melalui penerapan metode tanya jawab dengan variasi media pembelajaran untuk meningkatkan hasil belajar siswa.

Dalam penelitian ini dilakukan sebanyak dua kali siklus, yaitu siklus I dilaksanakan 1 kali pertemuan yaitu pada tanggal 23 maret 2019, sedangkan siklus II dilaksanakan pada tanggal 16 april 2019. Kegiatan pembelajaran dari siklus dalam penelitian ini terbagi pada tiga kegiatan, yaitu kegiatan awal, inti dan akhir.

Dapat simpulkan bahwa dalam penelitian ini peneliti membagi 3 kegiatan utama, yaitu kegiatan awal, inti, dan akhir. Dalam hal ini kegiatan awal meliputi pembelajaran salam menyapaikan tujuan pembelajaran, apersepsi dan motivasi.

Penerapan metode Tanya jawab dengan variasi media pembelajaran pada mata pelajaran PPKN materi Daerah dalam Kerangka NKRI kelas VII D SMP Dwijendra Denpasar. Penerapan metode Tanya jawab pada materi "Daerah dalam Kengaka NKRI" di kelas VII D SMP Dwijendra Denpasar. Peneliti memberikan salam untuk membuka pembelajaran kemudian melakukan tanya jawab seputar materi kemudian meminta siswa untuk menyampaikan pendapat.

Setelah itu peneliti membagi beberapa kelompok yang terdiri atas 5 kelompok .Kemudian peneliti membagikan lembar kerja kelompok kerja kepada masing-masing kelompok dan meminta setiap kelompoknya untuk melakukan diskusi dengan kelompoknya. Peneliti memvasilitasi siswa untuk mempresentasikan hasil kerjanya, siswa yang laim memberikan komentar atau tanggapan.

Peningkatan hasil belajar siswa dengan diterapkannya penerapan metode Tanya jawab banyak siswa menjadi meningkat. Selama pelaksanaan pembelajaran mulai dari pre test, test siklus I sampai siklus II.Dari uraian di atas dapat ditarik simpulan bahwa penerapan metode Tanya jawab dengan variasi media pembelajaran dapat meningkatkan hasil belajar siswa. 


\section{PENUTUP}

Berdasarkan penelitian dan pembahasan dapat dibuat simpulan sebagai berikut: (1) Pelaksanaan penerapan metode tanya jawab dengan variasi media pembelajaran pada mata pelajaran PPKN kelas VII D SMP Dwijendra Denpasar. Pada pelaksanakan siklus I dan II tahap-tahap tersebut telah dilaksanakan dan memberikan perbaikan yang positif dalam diri siswa, Hal tersebut dapat dibuktikan dengan keaktifan siswa dalam mengikuti pelajaran PPKN dikelas, contohnya siswa yang semulanya pasif menjadi aktif, hal ini dibuktikan dengan paparan data keaktivan siswa saat mengikuti proses proses pembelajaran dengan metode tanya jawab, (2) Penggunaan penerapan metode Tanya jawab ternyata mampu meningkatkan hasil belajar siswa kelas VII SMP Dwijendra Denpasar Tahun Pelajaran 2018/2019, Peningkatan belajar siswa juga dapat dilihat dari kreteria kentuntasan minimal (KKM) yang ditetapkan adalah 80. Terbukti pada hasil pre test dari 31 siswa yang ikut test, hanya 18 siswa yang tuntas belajar dan 13 siswa yang tidak tuntas belajar, dengan presentase ketuntasan 45,16\%. Meningkat pada hasil test siklus I dari 31 siswa yang ikut test ada 18 siswa yang tuntas belajar dan 13 siswa yang belum tuntas belajar dengan presentase ketuntesan 58.06\%. Dan meningkat dengan sangat tajam pada siklus II dari 31 siswa yang mengikuti test 28 siswa yang tuntas belajar dengan presentase $93,54 \%$.

\section{DAFTAR PUSTAKA}

Darwati, Mas \& Mahendra, Putu Ronny Angga. 2019. Efektivitas Pembelajaran PPKn Berbasis Teknohumanistik Dalam Pembentukan Karakter Siswa Kelas X Jasa Boga 2 di SMK Prshanti Nilayam Kuta Tahun Pelajaran 2017/2018. Singaraja: FHIS Universitas Pendidikan Ganesha.

Davies,Ivor k.1987.Pengelolaan Belajar.Jakarta:C.V Rajawali dan PAUUT

Djamarah dan Azwan Zain. 2010. Strategi Belajar Mengajar. Jakarta : Rineka Cipta.

Departemen Pendidikan Dan Kebudayaan.1995.Panduan Pengajaran PPKn.Jakarta

Hamalik, Oemar. 2010. Proses Belajar Mengajar. Jakarta : Bumi Aksara

Ibrahim . 2009. Strategi Pembelajaran. Jakarta : Bumi Aksara

Kaelan, 2002, Filsafat dan Bahasa, Masalah dan Perkembangannya, Yogyakarta: Paradigma.

Mahendra, Putu Ronny Angga. Pembelajaran PPKn Dalam Resonansi Kebangsaan dan Globalisasi. Jurnal Ilmiah Ilmu Sosial. Singaraja : Universitas Pendidikan Ganesha.

Sujana, nana,2009. Penilaian Hasil Proses Belajar Mengajar. bandung

Surbakti, Ramlan, Ideologi Sebagai Dasar Negara. Jakarta : Gramedia Widya Sarana, 1992

Winaya, Astra,2017. “Efektivitas Pengembangan Nilai-nilai Karakter Pada Peserta Pesraman Kilat Tingkat Dasar di Desa Pekraman Selan Bawak, Keamatan Marga,Kabupaten Tabanan-Bali. ’Jurnal Widya Accarya.Fakultas Keguruan dan Ilmu Pendidikan Universitas Dwijendra, EJurnal.ac.id., Denpasar 